\title{
Impact of plasma histones in human sepsis and their contribution to cellular injury and inflammation
}

Michael Liembo Ekaney ${ }^{1}$, Gordon Philipp Otto ${ }^{1,2}$, Maik Sossdorf ${ }^{1,2}$, Christoph Sponholz ${ }^{1,2}$, Michael Boehringer ${ }^{1,3}$, Wolfgang Loesche ${ }^{1,2}$, Daniel Rittirsch ${ }^{4}$, Arne Wilharm ${ }^{5}$, Oliver Kurzai ${ }^{1,3}$, Michael Bauer ${ }^{1,2}$ and Ralf Alexander Claus ${ }^{1,2^{*}}$

\begin{abstract}
Introduction: Circulating histones have been identified as mediators of damage in animal models of sepsis and in patients with trauma-associated lung injury. Despite existing controversies on actual histone concentrations, clinical implications and mechanism of action in various disease conditions, histone levels in human sepsis, association with disease progression and mediated effects on endothelial and immune cells remain unreported. This study aimed to determine histone levels and its clinical implication in septic patients and to elucidate histone-mediated effects ex-vivo.

Methods: Histone levels, endogenous activated protein C (APC) levels and clinical data from two independent cohorts of septic patients were obtained. Histone levels were compared with various control groups including healthy individuals, intensive care unit (ICU) patients without sepsis, ICU patients with multiple organ failure and patients with minor or multiple trauma, all without infection. Endothelial and monocytic cells were stimulated with histones. Cellular integrity and sepsis prototypical cytokines were evaluated. The mechanism of action of histones via Toll-like receptor 4 (TLR4) was evaluated using a function blocking antibody. Histone degradation in plasma was studied by immunoblotting.
\end{abstract}

Results: Histone H4 levels were significantly elevated in patients with sepsis (cohort I; $n=15$ and cohort II; $n=19$ ) versus ICU controls $(n=12)$, patients with multiple organ failure $(n=12)$ or minor trauma $(n=7)$, associated with need for renal replacement therapy and decrease in platelet count during disease progression, and remarkably were significantly associated with increased mortality rates in septic patients (ICU-, 28 day- and 90 day mortality rates). There was an inverse correlation between plasma histones and endogenous APC levels. Histone stimulation induced the release of sepsis prototypic cytokines and decreased cell integrity indicated by a significant increase of lactate dehydrogenase (LDH) and propidium iodide (PI) staining. Blocking of TLR4 decreased cellular cytotoxicity on endothelial cells. The calculated half-life of histones in spiked plasma was 4.6 minutes.

Conclusions: Histone levels in septic patients are significantly increased and might mediate disease aggravation by cellular injury and inflammation via TLR4 signaling, which potentially results in multiple organ failure and fatal outcome.

\footnotetext{
* Correspondence: ralf.claus@med.uni-jena.de

${ }^{1}$ Center for Sepsis Control and Care (CSCC), Jena University Hospital, Erlanger

Allee 101, Jena, Germany

${ }^{2}$ Clinic for Anesthesiology and Intensive Care, Jena University Hospital,

Erlanger Allee 101, Jena, Germany

Full list of author information is available at the end of the article
} 


\section{Introduction}

Sepsis is a multifactorial life-threatening syndrome arising from the immune response to invading microorganisms, resulting in excessive cell activation and tissue damage [1,2]. Based on current understanding of the pathophysiology of the host response, endothelial activation and dysfunction [3], as well as culminating multiple organ failure, are known hallmarks of the clinical course, which determines the prognosis of patients [4-6]. Multiple immune activators during systemic inflammation known as pathogen-associated molecular pattern (PAMPs) [7] and damage-associated molecular patterns (DAMPs) [8] have been reported to be involved in the aggravation of host response.

Recently reported is a concept implicating extracellular histone isoforms, mainly histone $\mathrm{H} 4(\mathrm{H} 4)$, as a result of host response, which aggravates maladaptive mechanisms through a direct action on endothelial cells [9] and platelets [10]. Furthermore, free histones in circulation mediate extensive cellular damage, hemostatic imbalance and amplification of the inflammatory response by inducing cytokine production as reported in an animal model of sepsis. Intravenous injection of purified histones in mice elicited thrombocytopenia, neutrophil migration, and organ failure mimicking the pathophysiological signature of sepsis [9]. Interestingly, co-infusion of histones with APC [9] or intravenous injection of histones in toll-like receptor (TLR)4-null mice abrogates histone induced effects [11]. Additionally, histones have been reported to mediate fatal liver injury in mice [11], and have recently been identified as essential effectors of C5aR- and C5L2-mediated tissue damage and inflammation in acute lung injury [12] and in trauma-associated lung injury in humans, with concentrations ranging between 10 and $280 \mu \mathrm{g} / \mathrm{ml}$ as measured using immunoblotting [13].

In this study, we sought to investigate histone levels in septic patients and associations with clinical data and activated protein $\mathrm{C}$ (APC). In vitro, we investigated the role of histones in cellular damage, inflammatory response and their interaction with TLR4, using functional blocking antibody.

\section{Materials and methods Clinical study}

Institutional ethical approval was given by the local ethics committee of the medical faculty of Friedrich-Schiller University Hospital in Jena (2160-11/07, 2712-12/09) and the local ethics committee Zurich (kantonale Ethikkommission Zürich, KEK: StV26-2007), and written informed consent of each patient was obtained.

ICU controls and patients with severe sepsis or septic shock according to the American College of Chest Physicians and the Society of Critical Care Medicine (ACCP/
SCCM) [14] were prospectively enrolled. Cohort I included 15 patients with sepsis from various origins during disease progression. Cohort II included 19 patients suffering from postoperative anastomosis insufficiency after major abdominal surgery (Table 1). Blood samples were collected in citrated anticoagulant tubes within 24 hours at onset of sepsis (day 1) in cohort I and at onset of sepsis, and on day 3 and day 5 in cohort II. Plasma was separated by centrifugation at $2000 \times \mathrm{g}$ for 10 minutes. Patient characteristics from both cohorts were obtained (Table 1). Additionally, various clinical scores and laboratory findings including age, sex, International classification of Disease $10^{\text {th }}$ revision (ICD-10) diagnosis, length of stay (LOS), outcome, acute physiology and chronic health evaluation II score (APACHE II), simplified acute physiology score (SAPS), sequential organ failure assessment score (SOFA), ventilator assistance, vasopressor treatment, creatinine levels and requirement for renal replacement therapy (RRT), bilirubin, C-reactive protein (CRP), partial thromboplastin time (PTT), platelet count, leukocyte count and procalcitonin levels were obtained from the patient data monitoring system. Platelet increase was defined as an increase in platelet count $>30 \%$ on day 5 of sepsis progression as compared to platelet count on day 1 , while platelet decrease was defined as a fall in platelet count $>30 \%$ on day 5 of sepsis as compared to platelet count at onset of sepsis.

For comparison of histone concentrations, we included various control groups, which included; 5 healthy individuals, $12 \mathrm{ICU}$ patients without sepsis, $12 \mathrm{ICU}$ patients with multiple organ failure (MOF), 7 patients with distal radius fracture (minor trauma), and 12 patients with multiple trauma (nonconsecutive patients with thoracic injury; age: median 73 years, range 42 to 92 years; injury severity score (ISS): median 34, range 17 to 66; with blunt chest trauma; male/female: $8 / 3$; lethality $27.3 \%[3 / 11])$. The control groups showed no signs of

\section{Table 1 Clinical characteristics of patients at study} enrollment

\begin{tabular}{lll}
\hline Patient characteristics & Cohort I & Cohort II \\
\hline Number of patients (n) & 15 & 19 \\
Age, years, median (IQR) & $72(48$ to 77$)$ & $69(45$ to 73$)$ \\
Gender male, n (\%) & $8(53.3)$ & $13(68.4)$ \\
ICU survivor, n (\%) & $10(66.7)$ & $12(63.2)$ \\
28-day survivors, n (\%) & n.d. & $14(73.7)$ \\
90-day survivors, n (\%) & n.d. & $7(36.8)$ \\
APACHE-II, median (IQR) & $24(18$ to 30$)$ & $19(15$ to 26$)$ \\
SAPS-II, median (IQR) & $44(33$ to 73$)$ & $44(34$ to 52$)$ \\
SOFA, median (IQR) & $10(6$ to 13$)$ & $10(6$ to 11$)$ \\
\hline
\end{tabular}

APACHE II, acute physiology and chronic health evaluation II; SAPS, simplified acute physiology score; SOFA, sequential organ failure assessment score. n.d. not determined. 
acute infection. Collection of trauma samples was performed following completion of other groups.

\section{Enzyme-linked immunosorbent assay (ELISA)}

Human histone $\mathrm{H} 4$ and APC ELISA kits were obtained from USCN Life Science (Wuhan, China). Standards and patient samples were run in duplicates according to manufacturer's instructions.

\section{Stimulation assays}

Commercially available calf thymus histones (Sigma, Deisenhofen, Germany) were passed through a high affinity endotoxin detoxi-gel (Thermo Fisher Scientific, Waltham, Massachusetts, USA) before use in all stimulation assays to remove potential endotoxin contamination. Purified calf thymus histones were used for stimulatory experiments on immortalized human microvascular endothelial cells (HMEC) and human monocytic cells (MM6). For in vitro assays, 500,000 cells per well seeded in six-well plates were stimulated with $10 \mathrm{ng} / \mathrm{ml}$ and $50 \mu \mathrm{g} / \mathrm{ml}$ of histones in cell culture media supplemented with $1 \%$ fecal calf serum. Unstimulated cells were used as negative control. Experiments were performed at least in triplicates.

\section{Human TLR4 neutralization}

Functional antibody against human TLR4 (PAb hTLR4) and control antibody (PAb Control) were obtained from Invivogen (San Diego, CA, USA). A total of 25,000 cells were seeded in 96-well plates. Antibodies were diluted to a final concentration of $5 \mu \mathrm{g} / \mathrm{ml}$ and incubated at $37^{\circ} \mathrm{C}$ for 10 minutes. A $50 \mu \mathrm{g} / \mathrm{ml}$ histone concentration was used for stimulation and cells were incubated overnight for 24 hours. Supernatant was collected for lactate dehydrogenase (LDH) measurements and cells were stained with propidium iodide (PI).

\section{Fluorescent staining (Propidium iodide staining)}

Cells were detached with $1 \mathrm{X}$ trypsin and washed three times with $1 \mathrm{X}$ sterile PBS. Cells were resuspended in $1 \mathrm{ml}$ of $1 \mathrm{X}$ PBS and incubated with $10 \mu \mathrm{g} / \mathrm{ml}$ PI dye solution (Sigma, St. Louis, USA) in the dark for 5 minutes at room temperature. Fluorescent intensity was measured by flow cytometry.

\section{Lactate dehydrogenase measurement}

LDH levels in cell culture supernatant were measured at 0 hours and 24 hours after histone stimulation with a commercially available kit (Roche, Germany) according to manufacturer's instructions. Absorbance was read at $490 \mathrm{~nm}$ using a spectrophotometer.

\section{Cytokine measurements}

For quantification of cytokines in cell culture supernatant after histone stimulation, a cytometric bead assay
(CBA) was performed according to the manufacturer's instructions (human inflammation kit; BD Biosciences, Germany) and measured by flow cytometry using a FACS calibur.

\section{Determination of histone stability}

Blood from three healthy volunteers was drawn into citrated anticoagulant tubes and plasma was separated by centrifugation at $2000 \times \mathrm{g}$ for 10 minutes. Plasma was spiked with calf thymus histones to a concentration of $100 \mu \mathrm{g} / \mathrm{ml}$ and incubated at $37^{\circ} \mathrm{C}$ with mild shaking for $5,10,15$ and 30 minutes. Plasma was separated by western blotting and detection of histones was performed using anti-histone $\mathrm{H} 3$ antibodies (Cell signalling, USA). Determination of half-life was performed by approximation of the degradation process reaching a plateau phase.

\section{Statistical analysis}

Levels of histone measurements are given as median including the $25^{\text {th }}$ and $75^{\text {th }}$ IQR. Analysis of variance (ANOVA) on ranks was used to determine differences between histone concentrations at onset of sepsis, day 3 and day 5 . The Student $t$-test or Mann-Whitney test was used to compare independent variables where applicable. Multivariate linear regression analysis was used to predict clinical characteristics that were independently associated with histone levels. Spearman correlation coefficient $(r)$ was used to determine the correlations between independent parameters and histone levels. Statistical significance was set at $P<0.05$. Densitometry analysis was performed using AIDA software and a single-phase decay analysis for calculation of half-life was performed using Graph Pad Prism 5.0.

\section{Results}

Histone levels in septic patients correlate with disease progression and mortality

In cohort I, histone $\mathrm{H} 4$ levels were significantly elevated compared to ICU controls (sepsis cohort I: median 0.35, IQR 0.2 to 0.46$)$ versus ICU controls: median 0.06 (0.05 to 0.07$) \mathrm{ng} / \mathrm{ml}, P<0.05$; Figure $1 \mathrm{~A})$. In cohort II, histone $\mathrm{H} 4$ levels were significantly elevated during the course of sepsis on day 1 , day 3 and day 5 as compared to the ICU control group (sepsis cohort II, day 1: median 0.37 (0.16 to 0.61$)$, day 3: median 0.28 (0.08 to 0.53$)$, day 5 : median 0.41 (0.22 to 0.62$)$ versus ICU controls: median $0.06(0.05$ to 0.07$) \mathrm{ng} / \mathrm{ml}, P<0.05$; Figure $1 \mathrm{~A})$. Histone concentrations in both cohorts ranged from 0.01 to $1.08 \mathrm{ng} / \mathrm{ml}$ with an inter-assay coefficient of variation (CV) $<10 \%$. However, detection of histones in plasma of patients by immunoblotting was not possible because the observed concentrations were far below the limit of detection by this method (approximately 500 


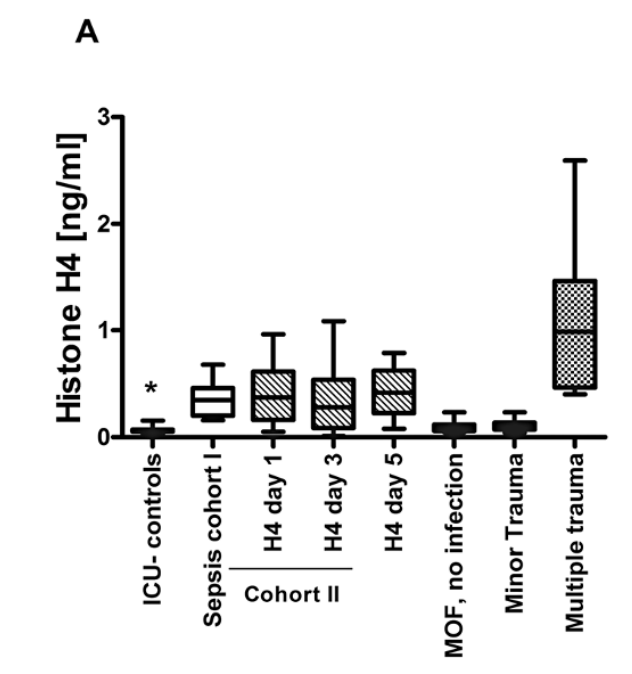

\section{B}

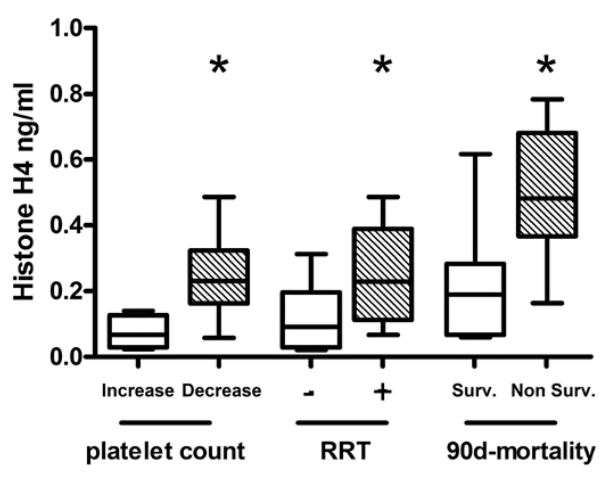

Figure 1 Plasma histone $\mathrm{H} 4$ concentration in two independent cohorts of septic patients (Cohorts I and II) and associations with disease progression and mortality. (A) Plasma histone concentration in sepsis cohort I $(n=15)$ and sepsis cohort II $(n=19)$ on day 1, day 3, day 5 , ICU controls $(n=12)$, patients with multiple organ failure (MOF) $(n=12)$, minor trauma $(n=7)$ and multiple trauma $(n=12)$ patients. All controls were without signs of infection. *Mann-Whitney test $(P<0.05)$ to compare independent groups. (B) Plasma histone $\mathrm{H} 4$ at day 1 associated with platelet count at day 5 , requirement for renal replacement at day 5 , and outcome at day 90 . ${ }^{*}$ Mann-Whitney test, $P<0.05$. RRT ${ }^{+}$indicates the requirement of renal replacement therapy; RRT indicates no requirement for renal replacement therapy.

$\mathrm{ng} / \mathrm{ml})$. Histone levels on day 1 in both cohorts of septic patients were also significantly elevated compared to patients with MOF (sepsis cohort I: median 0.35 (IQR 0.2 to 0.46$)$, sepsis cohort II: median 0.37 (0.16 to 0.62 ) versus MOF: median 0.08 (IQR 0.05 to 0.11 ) ng/ $\mathrm{ml}, P<0.05)$ and minor trauma patients (sepsis cohort I: median 0.35 (IQR 0.2 to 0.46 ), sepsis cohort II: median 0.37 (0.16 to 0.62 ) versus minor trauma: median 0.11 (IQR 0.07 to 0.13 ) ng/ml, $P<0.05$ ). However, histone levels in multiple trauma patients were 3 -fold higher than levels measured in septic patients with concentrations up to $3 \mathrm{ng} / \mathrm{ml}$ (multiple trauma: median 0.98 (IQR 0.46 to 1.46 ) versus sepsis cohort I: median 0.35 (IQR 0.2 to 0.46 ), sepsis cohort II: median 0.37 $(0.16$ to 0.62$) \mathrm{ng} / \mathrm{ml}, P<0.05$, Figure $1 \mathrm{~A})$.

Analyses of the clinical data from cohort II revealed that patients with a decline in platelet count $>30 \%$ on day 5 of sepsis progression demonstrated significantly elevated histone levels on day 1 compared to patients with an increase in platelet count $>30 \%$ (decreased platelets: median 0.23 (0.16 to 0.32$)$ versus increased platelets: median 0.06 (0.02 to 0.12$) \mathrm{ng} / \mathrm{ml}, P<0.05$; Figure $1 B)$. Due to unvaried platelet count over time, two patients were not included in this subgroup analysis. Furthermore, patients who required RRT until day 5 presented significantly elevated histone levels on day 1 as compared to patients without subsequent need for RRT (need for RRT: median 0.23 (0.11 to 0.38 ) versus without need for RRT: median 0.09 (0.02 to 0.19$) \mathrm{ng} / \mathrm{ml}, P<0.05$; Figure 1B). With respect to ICU- and 28-day mortality, on day 1 non-survivors presented with significantly elevated concentrations compared to survivors (ICU mortality, non survivors: median 0.54 (0.34 to 0.71$)$ versus survivors: median 0.21 ( 0.06 to 0.4$) \mathrm{ng} / \mathrm{ml}, P<0.05$; 28 -day mortality, non survivors: median 0.67 ( 0.25 to 0.75$)$ versus survivors: median 0.25 (0.07 to 0.45$) \mathrm{ng} / \mathrm{ml}, P<0.05)$. Remarkably, this was also evident for 90-day mortality (non-survivors: median 0.48 (0.36 to 0.68$)$ versus survivors: median 0.19 (0.06 to 0.28$) \mathrm{ng} / \mathrm{ml}, P<0.05$; Figure $1 \mathrm{~B})$. Multivariate linear regression analysis including APACHE-II score, SOFA score, CRP, white blood cells (WBC), creatinine, and platelet count as independent variables identified WBC $\left(P<0.05, R^{2}=\right.$ $0.64)$ and SOFA score $\left(P<0.05, R^{2}=0.64\right)$ as predictors for histone levels at onset of sepsis (day 1 ).

Histone levels negatively correlate with endogenous APC Endogenous APC levels in cohort II at day 1, day 3 and day 5 were analyzed. APC levels were significantly elevated as compared to healthy controls (day 1: median 6.14 (IQR 5.8 to 6.9), day 3: median 6.49 (6.06 to 8.10), day 5: median 7.15 (5.21 to 7.68$) \mathrm{ng} / \mathrm{ml}$ versus controls: median 4.69 (4.16 to 5.51$) \mathrm{ng} / \mathrm{ml} ; P<0.05$; Figure $2 \mathrm{~A}$ ). APC levels were inversely correlated with histone levels $(r=-0.584, P<0.05$; Figure $2 \mathrm{~B}$ ). Furthermore, elevated APC levels were identified as an independent predictor of decreased histone levels when included in the multivariate linear regression model $\left(P<0.001, R^{2}=0.723\right)$.

\section{Histones mediate cellular damage and induced the cytokines production}

The cytotoxic effects of histones on endothelial cells and monocytes using $10 \mathrm{ng} / \mathrm{ml}$ and $50 \mu \mathrm{g} / \mathrm{ml}$ histone concentration were evaluated. There was no change in $\mathrm{LDH}$ release 

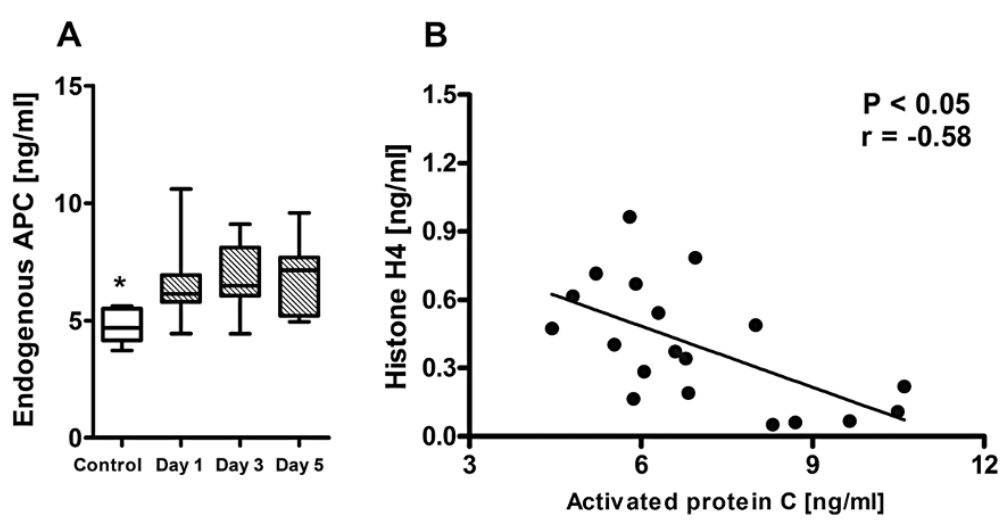

Figure 2 Endogenous APC levels in patients with sepsis and correlation with plasma histone levels. (A) Endogenous activated protein C (APC) levels in patients at onset of sepsis (day 1), day 3 and day 5. *Analysis of variance on ranks test $(P<0.05)$ to compare difference between APC levels on day 1, day 3 and day 5. (B) Endogenous APC levels negatively correlated with plasma histone levels. *Spearman correlation $(P<0.05)$.

or PI fluorescence of the nuclei after stimulation with $10 \mathrm{ng} /$ $\mathrm{ml}$. Histone concentration of $50 \mu \mathrm{g} / \mathrm{ml}$ led to cell death indicated by significant high levels of LDH and PI positive cells $(P<0.001)$ (Figure 3A-D). The stimulation of monocytes with $10 \mathrm{ng} / \mathrm{ml}$ histone concentration led to a significant increase in TNF- $\alpha$ at 6 hours and IL- 8 (6 hours, 24 hours, $P<0.05)$ while $50 \mu \mathrm{g} / \mathrm{ml}$ histones led to a marked increase in sepsis-associated cytokines such as TNF- $\alpha$, IL-6, IL-8, and IL- $1 ß$ at 6 hours and IL- 6, IL- 8 , and IL- $1 ß$ at 24 hours (Figure 4A-D).

\section{Blocking anti-TLR4 antibodies inhibits histone-induced cytotoxicity}

To evaluate the mode of action of histones, TLR4 signaling via receptor neutralization was targeted. Pretreatment of endothelial cells with a specific TLR4 blocking antibody abrogated histone-induced increase of cellular cytotoxicity as shown by both PI staining and measurement of LDH release $(P<0.05)$ after stimulation with $50 \mu \mathrm{g} / \mathrm{ml}$ histones (Figure $5 \mathrm{~A}-\mathrm{B}$ ).
A

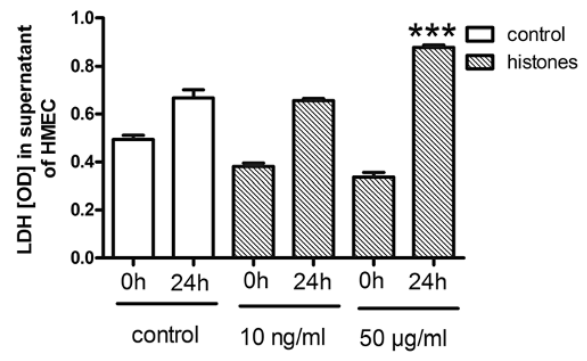

C

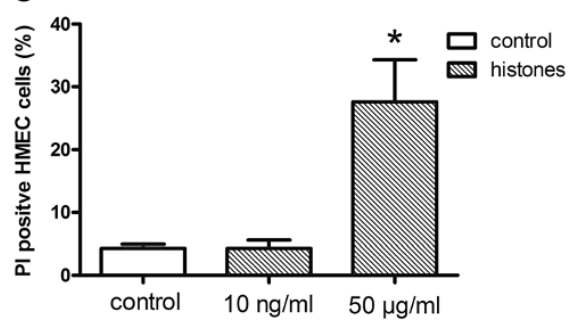

B
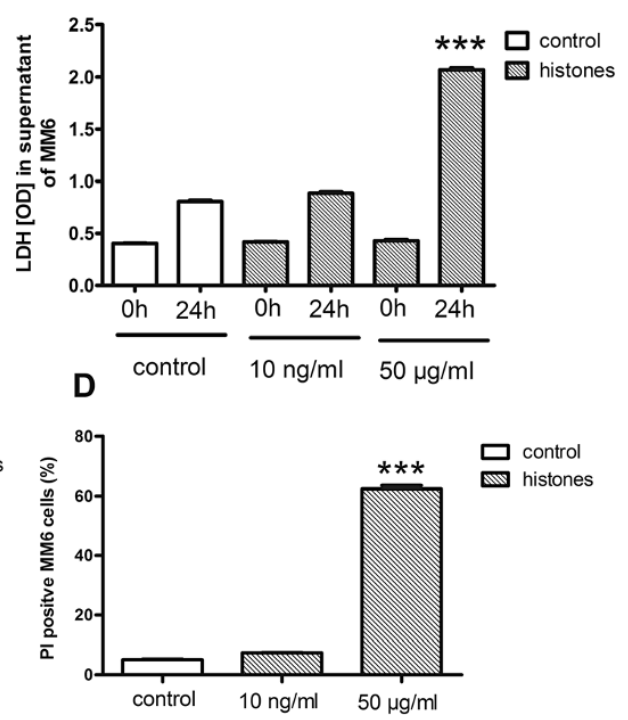

Figure 3 Evaluation of cellular integrity and viability after histone stimulation of endothelial and monocytic cells. (A) Lactate dehydrogenase $(\mathrm{LDH})$ levels significantly increased in supernatant of human microvascular endothelial cells (HMEC) after $50 \mu \mathrm{g} / \mathrm{ml}$ histones stimulation for $24 \mathrm{~h}$. ***Student's t-test, $P<0.001$. (B) LDH levels significantly increased in supernatant of mono mac 6 (MM6) cells after $50 \mu \mathrm{g} / \mathrm{ml}$ histones stimulation for 24 h. ${ }^{* * *}$ Student's $t$-test, $P<0.001$. (C) Percentage of propidium iodide (PI)-positive HMEC cells significantly increased after 24 hours stimulation with $50 \mu \mathrm{g} / \mathrm{ml}$ histones. *Student's t-test, $P<0.05$. (D) Percentage of Pl-positive MM6 cells significantly increased after 24 hours stimulation with $50 \mu \mathrm{g} / \mathrm{ml}$ histones. ${ }^{* * *}$ Student's $t$-test, $P<0.001$. 

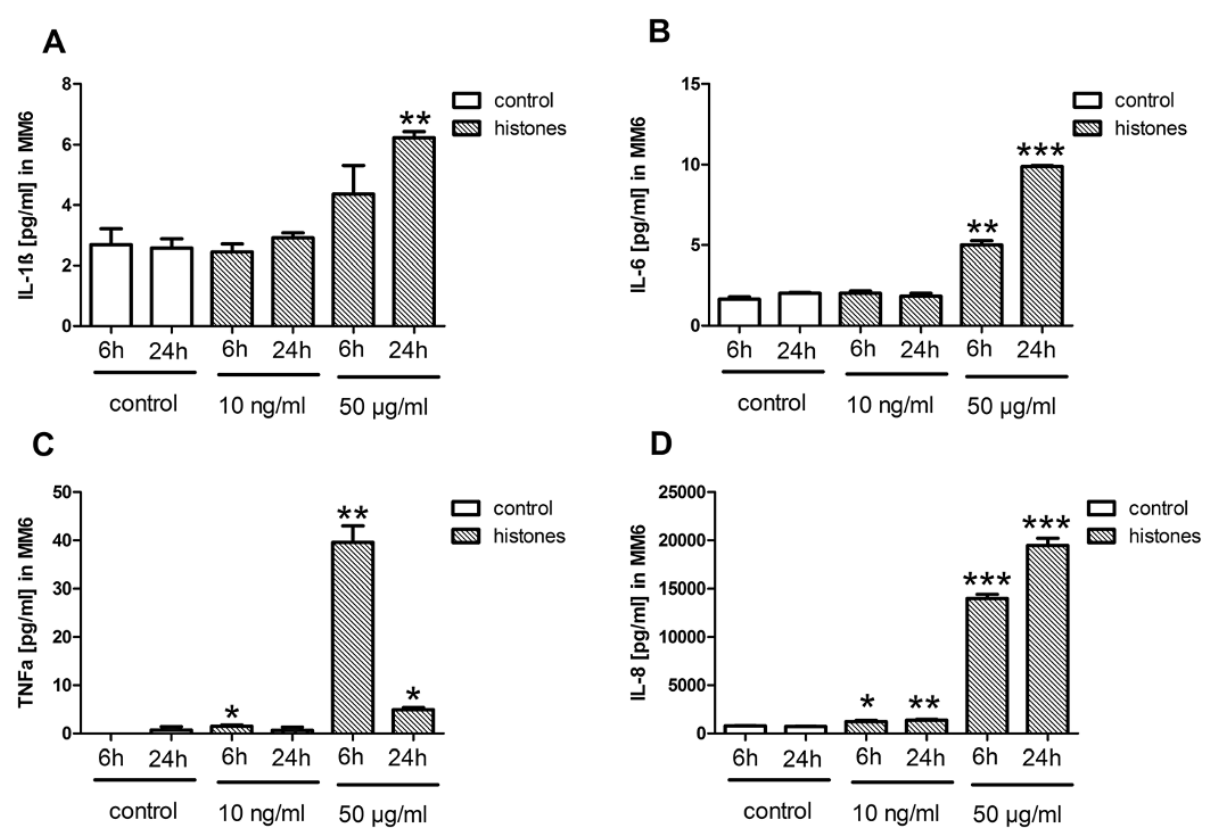

Figure 4 Cytokine production after histone stimulation. (A) IL-8 levels in supernatant from mono mac 6 (MM6) significantly increased after $10 \mathrm{ng} / \mathrm{ml}(P<0.05)$ and $50 \mu \mathrm{g} / \mathrm{ml}$ stimulation for 6 and 24 hours. ${ }^{* *}$ Student's $t$-test, $P<0.001$. (B) IL-1ß levels in supernatant from MM6 significantly increased after $50 \mathrm{mg} / \mathrm{ml}$ stimulation for 24 hours. ${ }^{*}$ Student's $t$-test, $P<0.05$. (C) IL-6 levels in supernatant from MM6 significantly increased after 50 $\mu \mathrm{g} / \mathrm{ml}$ stimulation for 6 and 24 hours. ***Student's $t$-test, $P<0.001$. (D) TNF-a levels in supernatant from MM6 increased after 6 hours with $10 \mathrm{ng} / \mathrm{ml}$ and $50 \mu \mathrm{g} / \mathrm{ml}$ histone stimulation and $50 \mu \mathrm{g} / \mathrm{ml}$ stimulation after 24 hours. *Student's $t$-test, $P<0.05$.

\section{Determination of histone stability}

In histone-spiked plasma, histone degradation over time was measured by western blotting. We found a single nonlinear regression exponential decay of histones in plasma between 0 to 30 minutes. The half-life of histones in three independent plasma samples was $4.6 \mathrm{mi}-$ nutes with an $R^{2}$ of 0.9159 (Figure 6A-B). Interestingly, after 30 minutes, degradation reached a plateau and no further decline was observed up to 6 hours (data not shown).

\section{Discussion}

The study demonstrated for the first time and in two independent cohorts of septic patients that plasma concentrations of extracellular histones are elevated during human sepsis as compared to ICU controls. Interestingly, the observed concentrations are similar in both cohorts with low inter-assay variation. Histones were also significantly increased during the course of disease progression until day 5 of sepsis. This is in line with previous reports of an increase in histone concentration in
A

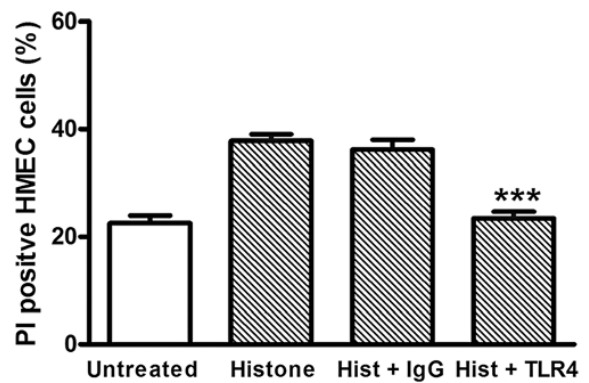

B

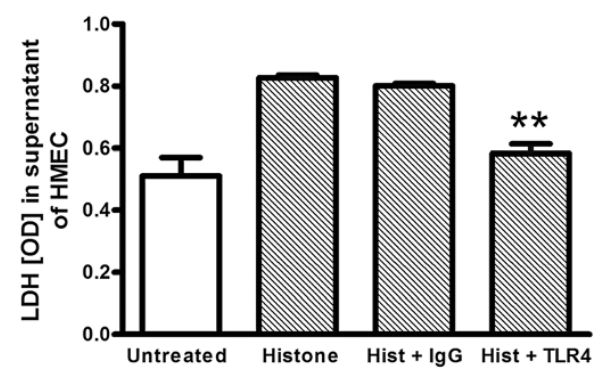

Figure 5 Histone effects after toll-like receptor 4 (TLR4) blockade. Blocking antibody control was obtained from animals housed under the same condition as immunized animals to produce TLR4 antibody. (A) Percentage of propidium iodide (PI)-positive human microvascular endothelial cells (HMEC) after 24 hours stimulation with $50 \mu \mathrm{g} / \mathrm{ml}$ histones with and without blocking of TLR4. ${ }^{* * * S t u d e n t ' s}$ $t$-test, $P<0.001$. (B) Lactate dehydrogenase $(\mathrm{LDH})$ release significantly decreased after blocking with specific TLR4 antibody compared to histone-stimulated cells. ${ }^{*}$ Student's $t$-test, $P<0.001$. 
A

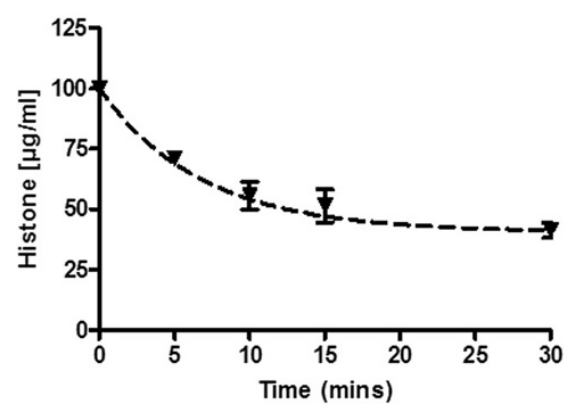

B

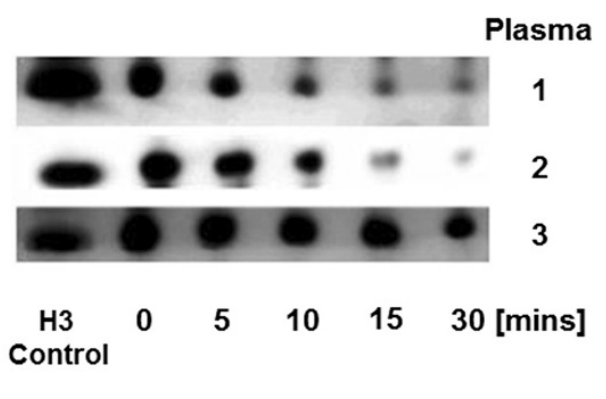

Figure 6 Estimated degradation kinetics of histones in plasma. (A) Single-phase exponential decay fit of three healthy individuals and the margin of error between samples. The half-life of histones ( $\mathrm{k}$ ) was 4.6 minutes with an $R^{2}=0.9159$. (B) Western blotting showed decrease in histone protein in plasma over time.

baboons after endotoxin challenge [9]. Interestingly, histone levels were higher in septic patients compared to patients with multiple organ failure without infection, potentially indicating that the source of histones in circulation could be strongly associated with the underlying infection and the release of neutrophil extracellular traps by neutrophils as demonstrated by others $[15,16]$. In addition, we found lower levels of histones in patients with minor trauma. This might be related to the limited tissue damage representing a lower release of histones into circulation, possible clearance of small quantities of histones in circulation by macrophages or complete eradication through active cleavage by proteases in plasma such as endogenous activated protein C. Most interestingly, we observed that in our cohort of patients with multiple trauma, histone concentrations were higher than levels found in septic patients. This supports previous reports of elevated levels of histones found in patients with blunt traumatic lung injury. Nevertheless, there was a clear disparity in the concentrations of histones measured in our multiple trauma patient cohort in the nanogram range compared to the levels reported in traumatic lung injury in the microgram range [13]. However, we could not confirm histone concentrations by mass spectrometry due to high abundance plasma proteins, which interfere with the detection of low abundance proteins despite the existence of high abundance protein depletion protocols. Our efforts to quantify histones by immunoblotting also failed because levels of histones found in patients were far below the lower limit of detection for immunoblotting ( $>500 \mathrm{ng} / \mathrm{ml}$ ). Nevertheless, our investigation using two independent cohorts of sepsis patients demonstrates and justifies consistency and reproducibility of plasma histone measurements in septic patients. In addition, the inclusion of a second cohort enabled us to determine plasma histones not only at onset of sepsis but also during disease progression.
A hallmark of sepsis is the occurrence of renal failure requiring renal replacement therapy [17]. Consistently, our data suggested that higher levels of histones correlated with the need for RRT. In addition, histones have been shown to bind to platelets recruiting plasma adhesion molecules, thereby promoting platelet aggregation [10]. In our study, increased histone levels were associated with a decrease in platelet count corroborating this concept. Interestingly, the occurrence of renal failure in sepsis and thrombocytopenia is often associated with high mortality $[18,19]$. The observed increase of plasma histone levels in patients undergoing RRT also implies that this increase might be a consequence of impaired renal excretion of the protein. However, to the best of our knowledge, there is no evidence that histones are excreted and become present in urine, either in healthy or pathophysiological conditions. On the other hand, microvascular permeability is increased when renal microvasculature is exposed to extracellular histones, released from dying tubular epithelial cells [20]. In lipopolysaccharide (LPS)-induced endotoxemia, neutralization of released histones reduced tubular injury and an improved renal function as measured by creatinine levels was obvious [20], identifying histones as mediators of acute kidney injury. Strikingly, higher histone levels correlated with ICU-, 28- and 90-day mortality. Interestingly, thrombocytopenia and organ dysfunction following histone administration have also been demonstrated in mice $[8,10]$. Based on this concept, it could be hypothesized that the interaction of histones with the endothelium will result in endothelial impairment. This damage leads to endothelial dysfunction promoting platelet activation and aggregation, which impairs microcirculation and results in organ dysfunction, which is associated with an increased risk of death [21]. In line with this, our ex-vivo findings further demonstrate that histone mediated cytotoxicity on endothelium cells and underline the results of Fuchs et al. demonstrating 
direct platelet activation and aggregation [10]. Besides the direct effects on platelets and cytotoxicity, we were able to show an activation of immune cells which led to an increase in sepsis prototypic cytokines in both low and high concentrations of histone stimulation. From a pathomechanistic perspective, histone mediated effects might be initiated by TLR4 signaling as neutralization or blocking of the TLR4 receptor in our study completely abrogated histonemediated cytotoxicity in our in vitro model. This underlines a report by Xu et al. who showed that TLR4 knock-out mice are protected from the fatal effects of histone infusion [11] and also, at least in part, is in line with results from Abrams et al. showing that TLR4 blocking results in a decrease in cytokine production but not cytotoxicity.

We report lower concentrations of histones in the nanogram range during sepsis which contradicts reports on the levels of histones measured in various species and diseases (baboons after gram-negative challenge, approximately 15 $\mu \mathrm{g} / \mathrm{ml}$ [9], in patients with blunt traumatic lung injury, approximately 10 to $280 \mu \mathrm{g} / \mathrm{ml}$ [13], $200 \mu \mathrm{g} / \mathrm{ml}$ in mice models of acute lung injury [12]) and reported concentration used in all histone stimulation studies so far (approximately 10 to $1000 \mu \mathrm{g} / \mathrm{ml})$ [9,11-13,22]. It could also be speculated that the discrepancy in histone levels released in animal (mice and baboons) sepsis and the actual concentration measured in plasma of our septic patients might be due to the treatment with heparin in our septic ICU patients. Heparin is highly negatively charged and was recently shown to bind to positively charged histones reducing their cytotoxic effect [22]. In line with other reports, the observed histone levels in multiple trauma patients might be related to a higher degree of tissue damage as represented by the injury severity score [13]. In our cohort stratified according to need for RRT on day 5 (cohort II), all of the patients underwent anticoagulation either with heparin (2/3 of all our ICU patients) or citrate (1/3 of all our ICU patients). However, measurements of histones to associate the level with the clinical endpoint of need for RRT were performed prior to initiation of anticoagulation for supportive treatment. From the low number of samples with different anticoagulants, from which one might interact with the readout, no comparison between these was performed.

We demonstrate also for the first time the ability of plasma to degrade histones. As plasma was used for these experiments, a potential binding of positively charged histones to negatively charged membranes of erythrocytes could be excluded. The observed fast initial degradation of histones might be related to free proteases within the plasma such as endogenous APC and might explain why co-injection of histones with APC abrogated the lethal effects of histone injection in mice [9]. This might also support our finding of a negative correlation between histone levels and APC in our septic patients. Unclear, however, is the decline to a steady state of histones in plasma after 30 minutes. However, we speculate that the biological half-life of histones in plasma could be affected by active metabolites, binding of fragments to other proteins as well as receptor interactions and therefore will not follow the first order kinetics with a fixed rate constant, because the generated fragments were also detected by the cited polyclonal antibodies. Nevertheless, this finding indicates the need for early centrifugation and measuring or freezing of the samples. Finally, further studies should elucidate the origin and sources of circulating histones in plasma during sepsis.

\section{Conclusions}

In conclusion, our data provides evidence that plasma histones are not only elevated in human sepsis but are associated with sepsis-related organ dysfunction, mediating cellular damage and severe inflammation responses. The observed effects might be mediated via the TLR4 receptor.

\section{Key messages}

- We analyzed histone concentrations in two independent cohorts of septic patients. Histone levels were significantly elevated in septic patients as compared to ICU controls but lower in patients with multiple trauma.

- Higher concentrations of histones associated significantly with lower endogenous APC levels, with the requirement for RRT, a decrease in platelet count and were found to be higher in 28- and 90-day non-survivors.

- In vitro, histone stimulation of cultured endothelial and monocytic cells decreased cellular integrity and resulted in an increase in septic prototypic cytokines.

- Histone-mediated action might be through TLR4. The half-life of histone degradation in plasma was 4.6 minutes.

\section{Abbreviations}

ACCP: American College of Chest Physicians; ANOVA: analysis of variance; APACHE: II acute physiology and chronic health evaluation II; APC: activated protein C; CBA: cytometric bead array; CRP: C-reactive protein; CV: coefficient of variation; DAMP: damage-associated molecular pattern; ELISA: enzyme linked immunosorbent assay; H4: histone 4; HMEC: human microvascular endothelial cells; ICD-10: International Classification of Disease 10th revision; IL: interleukin; LDH: lactate dehydrogenase; LOS: length of stay; MM6: mono mac 6; MOF: multiple organ failure; PAMP: pathogen-associated molecular pattern; PBS: phosphate buffered saline; PI: propidium iodide; PTT: partial thromboplastin time; RRT: renal replacement therapy; SAPS: simplified acute physiology score; SCCM: Society of Critical Care; SOFA: sequential organ failure assessment score; TLR4: toll-like receptor 4; TNF: tumor necrosis factor; WBC: white blood cells.

\section{Competing interests}

The authors declare that they have no competing interests.

\section{Authors' contributions}

MLE designed and performed experiments, analyzed data and wrote the first draft of the manuscript. GPO contributed to experimental design, interpreted 
data and reviewed the manuscript. MS contributed to the study concept and data acquisition. CS contributed to clinical study design and characterization of septic patients. AW characterized and collected samples from minor trauma patients. DR provided clinical samples from multiple trauma patients and contributed to the preparation of the manuscript. MBö contributed to the development of the study design and drafting of the manuscript. OK made critical contributions to the study and revised the manuscript. WL performed multivariate analyses and interpreted the data. MBa supervised the study and critically revised the manuscript. RAC supervised the study, revised and approved the final version of the manuscript. All authors read and approved the final manuscript. This study was supported by grants from the German Federal Ministry of Education and Research within the Center for Sepsis Control and Care (grant 01 EO 1002, Project D1.9; PhD fellowship to MLE.

\section{Acknowledgements}

We are grateful to Edith Walther and Brigitte Specht for excellent technical assistance and Jorge Hurtado for helpful discussion and recommendations.

\section{Author details}

${ }^{1}$ Center for Sepsis Control and Care (CSCC), Jena University Hospital, Erlanger Allee 101, Jena, Germany. ${ }^{2}$ Clinic for Anesthesiology and Intensive Care, Jena University Hospital, Erlanger Allee 101, Jena, Germany. ${ }^{3}$ Septomics Research Centre, Leibniz Institute for Natural Product Research and Infection Biology Hans Knoell Institute, Beutenbergstrasse 11a, 07745 Jena, Germany. ${ }^{4}$ Division of Trauma Surgery, University Hospital of Zurich, Raemistraße 100, CH-8091 Zurich, Switzerland. ${ }^{5}$ Department of Trauma, Hand and Reconstructive Surgery, Jena University Hospital, Erlanger Allee 101, D-07743, Jena 07747, Germany.

Received: 10 June 2014 Accepted: 11 September 2014 3.

\section{References}

1. Riedemann NC, Guo RF, Ward PA: Novel strategies for the treatment of sepsis. Nat Med 2003, 9:517-524.

2. de Jong HK, van der Poll T, Wiersinga WJ: The systemic pro-inflammatory response in sepsis. J Innate Immun 2010, 2:422-430.

3. Aird WC: The role of the endothelium in severe sepsis and multiple organ dysfunction syndrome. Blood 2003, 101:3765-3777.

4. Levi M, van der Poll T: Inflammation and coagulation. Crit Care Med 2010, 38:S26-S34.

5. Vincent JL: Acute kidney injury, acute lung injury and septic shock: how does mortality compare? Contrib Nephrol 2011, 174:71-77.

6. Gustot T: Multiple organ failure in sepsis: prognosis and role of systemic inflammatory response. Curr Opin Crit Care 2011, 17:153-159.

7. Kawai T, Akira S: The role of pattern-recognition receptors in innate immunity: update on Toll-like receptors. Nat Immunol 2010, 11:373-384.

8. Chan JK, Roth J, Oppenheim JJ, Tracey KJ, Vogl T, Feldmann M, Horwood N, Nanchahal J: Alarmins: awaiting a clinical response. J Clin Invest 2012, 122:2711-2719.

9. Xu J, Zhang X, Pelayo R, Monestier M, Ammollo CT, Semeraro F, Taylor FB, Esmon NL, Lupu F, Esmon CT: Extracellular histones are major mediators of death in sepsis. Nat Med 2009, 15:1318-1321.

10. Fuchs TA, Bhandari AA, Wagner DD: Histones induce rapid and profound thrombocytopenia in mice. Blood 2011, 118:3708-3714.

11. Xu J, Zhang X, Monestier M, Esmon NL, Esmon CT: Extracellular histones are mediators of death through TLR2 and TLR4 in mouse fatal liver injury. J Immunol 2011, 187:2626-2631.

12. Bosmann M, Grailer JJ, Ruemmler R, Russkamp NF, Zetoune FS, Sarma JV Standiford TJ, Ward PA: Extracellular histones are essential effectors of C5aR- and C5L2-mediated tissue damage and inflammation in acute lung injury. FASEB J 2013, 27:5010-5021.

13. Abrams ST, Zhang N, Manson J, Liu T, Dart C, Baluwa F, Wang SS, Brohi K, Kipar A, Yu W, Wang G, Toh CH: Circulating histones are mediators of trauma-associated lung injury. Am J Respir Crit Care Med 2013, 187:160-169.

14. Bone RC, Balk RA, Cerra FB, Dellinger RP, Fein AM, Knaus WA, Schein RM, Sibbald WJ: Definitions for sepsis and organ failure and guidelines for the use of innovative therapies in sepsis: the ACCP/SCCM Consensus
Conference Committee. American College of Chest Physicians/Society of Critical Care Medicine. 1992. Chest 2009, 136(5 Suppl):e28.

15. Neeli I, Khan SN, Radic M: Histone deimination as a response to inflammatory stimuli in neutrophils. J Immunol 2008, 180:1895-1902.

16. Brill A, Fuchs TA, Savchenko AS, Thomas GM, Martinod K, De Meyer SF, Bhandari AA, Wagner DD: Neutrophil extracellular traps promote deep vein thrombosis in mice. J Thromb Haemost 2012, 10:136-144.

17. Filiponi TC, de Souza Durao M Jr: How to choose the ideal renal replacement therapy in sepsis? Shock 2013, 39:50-53.

18. Vanderschueren S, De Weerdt A, Malbrain M, Vankersschaever D, Frans E, Wilmer A, Bobbaers $\mathrm{H}$ : Thrombocytopenia and prognosis in intensive care. Crit Care Med 2000, 28:1871-1876.

19. Marshall JC, Cook DJ, Christou NV, Bernard GR, Sprung CL, Sibbald WJ: Multiple organ dysfunction score: a reliable descriptor of a complex clinical outcome. Crit Care Med 1995, 23:1638-1652.

20. Allam R, Scherbaum CR, Darisipudi MN, Mulay SR, Hagele H, Lichtnekert J, Hagemann JH, Rupanagudi KV, Ryu M, Schwarzenberger C, Hohenstein B, Hugo C, Uhl B, Reichel CA, Krombach F, Monestier M, Liapis H, Moreth K, Schaefer $L$, Anders $H J$ : Histones from dying renal cells aggravate kidney injury via TLR2 and TLR4. J Am Soc Nephrol 2012, 23:1375-1388.

21. Padkin A, Goldfrad C, Brady AR, Young D, Black N, Rowan K: Epidemiology of severe sepsis occurring in the first $24 \mathrm{hrs}$ in intensive care units in England, Wales, and Northern Ireland. Crit Care Med 2003, 31:2332-2338.

22. Wildhagen KC, Garcia de Frutos P, Reutelingsperger CP, Schrijver R, Areste C, Ortega-Gomez A, Deckers NM, Hemker HC, Soehnlein O, Nicolaes GA: Non-anticoagulant heparin prevents histone-mediated cytotoxicity in vitro and improves survival in sepsis. Blood 2013, 21:21.

doi:10.1186/s13054-014-0543-8

Cite this article as: Ekaney et al:: Impact of plasma histones in human sepsis and their contribution to cellular injury and inflammation. Critical Care 2014 18:543.

\section{Submit your next manuscript to BioMed Central and take full advantage of:}

- Convenient online submission

- Thorough peer review

- No space constraints or color figure charges

- Immediate publication on acceptance

- Inclusion in PubMed, CAS, Scopus and Google Scholar

- Research which is freely available for redistribution

Submit your manuscript at www.biomedcentral.com/submit 